\title{
Derivation of quantitative management objectives for annual instream water temperatures in the Sabie River using a biological index
}

\author{
NA Rivers-Moore ${ }^{1 *}$, GPW Jewitt ${ }^{2}$ and DC Weeks ${ }^{1}$ \\ ${ }^{1}$ Institute for Water Research, Rhodes University, PO Box 94, Grahamstown 6140, South Africa \\ ${ }^{2}$ School of Bioresources Engineering and Environmental Hydrology, University of KwaZulu-Natal, P/Bag X01,
}

Scottsville 3209, South Africa

\begin{abstract}
Adaptive management of river systems assumes uncertainty and makes provision for system variability. Inherent within this management approach is that perceived limits of 'acceptable' system variability are regarded not only as testable hypotheses, but also as playing a central role in maintaining biodiversity. While the Kruger National Park currently functions as a flagship conservation area in South Africa, projected increases in air temperatures as a consequence of global climate change present challenges in conserving this biodiversity inside the established land boundaries. Within the rivers of the Kruger National Park, a management goal of maintaining biodiversity requires a clearer understanding of system variability. One component of this is water temperature, an important water quality parameter defining the distribution patterns of aquatic organisms. In this study, Chiloglanis anoterus Crass (1960) (Pisces: Mochokidae) was selected as a biological indicator of changes in annual water temperatures within the Sabie River in the southern Kruger National Park. Relative abundances of C. anoterus were determined using standard electro-fishing surveys. The presence or absence of $C$. anoterus was linked to cumulative annual heat units using a logistic regression model, and a critical annual cumulative water temperature threshold estimated. A correlative relationship between this temperature threshold and a biological index using a $C$. anoterus condition factor provides river ecologists with a tool to assess ecologically significant warming trends in Sabie River water temperatures. A similar approach could be applied with relative ease to other Southern African river systems. Further testing of this hypothesis is suggested, as part of the adaptive management cycle.
\end{abstract}

Keywords: Sabie River; daily maximum water temperature; Chiloglanis anoterus; condition factor index; adaptive management

\section{Introduction}

The importance of water temperatures to aquatic biota has been well-documented (for example Elliott, 1994; Eaton and Scheller, 1996; Claska and Gilbert, 1998; Sullivan et al., 2000). Furthermore, the accumulation of daily maximum temperatures above a critical threshold has been shown to have the greatest effect on the distribution and condition of aquatic species (Armour, 1991; Essig, 1998; Hines and Ambrose, 1998; Robison et al., 1999; Sullivan et al., 2000; Caissie et al., 2001). Biologically, daily maximum water temperatures are significant to fish, and in particular cold-water species, which show signs of acute stress at warm $\left(>22^{\circ} \mathrm{C}\right)$ water temperatures (Dunham et al., 2003). For example, Hines and Ambrose (1998) found that the best predictor for the presence or absence of coho salmon Oncorhynchus kisutch (Walbaum, 1792) was the number of days a site exceeded a critical temperature threshold, and that single temperature values correlated poorly with fish presence and absence.

However, fish presence is only one measure of individual success in an environment. While fish may persist, temperature conditions may be contributing to their decline, which will be manifested as a change in condition, reflecting responses to environmental stress (Hines and Ambrose, 1998). Thus, repeated

\footnotetext{
* To whom all correspondence should be addressed.

푱 +27466222428; fax:+27466229427; e-mail: nick@iwr.ru.ac.za Received 18 March 2005; accepted in revised form 11 August 2005.
}

and lasting exposure to sub-optimal thermal conditions leads to deterioration in condition. Hines and Ambrose (1998) proposed that a condition 'factor' could be linked to the number of days a threshold water temperature was exceeded. Such condition 'factors' are commonly used in biological studies to investigate seasonal and habitat differences in 'condition' or general 'wellbeing' (Ricker, 1968). Setting a water temperature threshold value based on the average condition of a population present at a site provides one method of determining 'unacceptable' water temperature conditions.

An approach such as this can provide river managers with a predictive tool when biotic responses to abiotic drivers are linked (Rivers-Moore, 2003), and have a degree of confidence in deciding when limits of natural variability are being exceeded. According to Rogers and Bestbier (1997), a 'primary problem facing scientists and managers in the Kruger National Park has been to develop the potential to predict and monitor the response of biodiversity in specific river sections (i.e. within the park) to modifications in hydrology, sediment supply and water quality originating at the catchment scale'. A key management challenge is to gain insight into change in complex natural systems, and to manage this change within so-called 'natural limits'. Adaptive management, based on managing natural systems through a process of careful testing of hypotheses rather than a reactive trial and error process (Walters, 1997), has been asserted as an approach to meeting this challenge.

Rogers and Bestbier (1997) provide a protocol for an adaptive management programme being implemented in the Kruger 
National Park, which provides a framework for translating 'visions' into reality through the implementation of hierarchically arranged goals and objectives. This 'objectives hierarchy' may be represented as a pyramid, which scales the management process from a vision (the apex of the pyramid) down to a broad base of management goals that relate to specific management objectives. A 'desired future state' for a system, such as a river, is defined, with incumbent goals, models and monitoring programmes (Rogers and Biggs, 1999). Inherent in this approach is recognition of the role of system variability such that management approaches remain flexible enough to adapt as new insights emerge.

Managing towards this 'desired future state' is facilitated through an iterative cycle wherein system change is monitored and compared against assumed thresholds of unacceptable change (TPCs or thresholds of probable concern) that set upper and lower limits of acceptable change for the environmental systems within the Park (Rogers and Bestbier, 1997). According to MacKenzie et al. (2000), TPCs define a range of acceptable change for chosen environmental drivers, and thus account for variability and heterogeneity exhibited by the system. Thus, TPCs are not fixed, but are modified if found to be invalid or inappropriate, and as such, can be considered as testable hypotheses on the limits of acceptable system change, based on the current level of scientific understanding.

Within this cycle, research identifies 'stressors' within the system, and suitable indicators of such change. Rogers and Bestbier (1997) suggest the use of biological indicators, which act as surrogates of measurable criteria that can be related to specific stressors (such as water temperatures) identified by conservation managers. The response of such indicators towards the stressors is measured against the relevant TPC, which is intended to providing natural resource managers with a decision-making tool to distinguish when natural variability is superseded by anthropogenic change. Change outside the limits of this acceptable variability is deemed 'TPC exceedance'. Should change be found to exceed the TPC, appropriate action may be taken, including reappraising the TPC, which is viewed as a hypothesis of the limits of acceptable change in ecosystem structure, function and composition (Rogers and Biggs, 1999).

The Sabie catchment is believed to be the most fish speciesrich river system in South Africa, with forty-nine species of fish. Water quality and quantity issues, and how they affect species diversity, are, however, poorly understood within the catchment (Weeks et al., 1996). Additionally, the Sabie catchment is under increasing threat from developments such as commercial afforestation, rural population growth, urban development and the construction of impoundments. Such pressures, in combination with anticipated global climate change scenarios of a doubling of $\mathrm{CO}_{2}$ levels and an associated $2^{\circ} \mathrm{C}$ increase in air temperatures by 2050 , make the Kruger National Park, as South Africa's flagship conservation area, vulnerable to species loss (Erasmus et al., 2002). Managing for variation in river flows and quality, in particular water temperatures, is a key factor in maintaining habitat integrity and species diversity.

The aim of this paper is to provide a generic approach for river managers to detect changes in annual thermal regimes which may be detrimental to aquatic biota, using the Sabie River as a case study. A spatially explicit TPC is proposed to address change in the annual water temperature range in the Sabie River, where exceedance is measured using a condition factor as a biological index. The biological index is based on the response of Chiloglanis anoterus Crass (1960) (Pisces: Mochokidae), an upstream cool water species, to annual changes in water temperatures, and can be used to indicate a change in the thermal regime of the Sabie River, by measuring species response to annual water temperatures over time at a particular spatial point.

According to Majer (1993), a species has potential value as an indicator if its presence is indicative of the existence of certain environmental conditions, whereas its absence is indicative of the absence of these conditions. C. anoterus was considered to be an appropriate indicator of annual thermal change in the Sabie River system, since this fish species met certain desirable criteria (Harris, 1995):

- $\quad$ Small size $=$ rapid response to thermal change

- Habitat specificity to riffles = likely to persist in thermally unsuitable habitat rather than migrating

- Ease of sampling in shallow, accessible riffle areas

Previous electro-fishing surveys undertaken in the Sabie River showed that $C$. anoterus, an abundant upstream species, is characterized by much reduced numbers in the warmer lowveld zone, with an associated decline in 'condition', in terms of a length to mass ratio (Weeks et al., 1996). Rivers-Moore (2003) also showed that $C$. anoterus was a suitable indicator species of thermal change, based on comparisons with an additional four species of fish occurring in the Sabie River using microhabitat requirements and niche overlaps. Rare species were not considered because their absence from a survey is likely to be due to their rarity as much as by their absence, i.e. they are not readily sampled.

The following assumptions have been made in this study:

- C. anoterus adult populations are widespread enough for these fish to act as an 'indicator' species for the fish communities in the Sabie River.

- The condition factor of C. anoterus is predominantly a function of cumulative thermal stress, although the compounding effect of additional abiotic and biotic factors is acknowledged (see, for example, Stuckenberg, 1969; Armour, 1991; Essig, 1998; Hines and Ambrose, 1998; Caissie et al., 2001).

- Changes in the indices of the chosen indicator species will be a precursor to a change in the fish community patterns as a whole.

Depending on how the 'desired future state' may have been defined within the adaptive management process, changes in the condition factor will assist in meeting the specific management goal of the Kruger National Park of maintaining biodiversity (Braack, 1997), by providing an objective means of measuring thermal stress within this river system.

\section{Methods}

\section{Study area}

The Sabie catchment $\left(24^{\circ} 30^{\prime} \mathrm{S} 30^{\circ} 30^{\prime} \mathrm{E}\right.$ to $\left.25^{\circ} 30^{\prime} \mathrm{S} 32^{\circ} 00^{\prime} \mathrm{E}\right)$ is situated in Mpumalanga Province, South Africa, and is approximately 709600 ha in size (Fig. 1). The main river within this catchment is the perennial Sabie River, with the Marite and Sand Rivers as its main tributaries. The altitude within this catchment ranges from $2130 \mathrm{~m}$ above mean sea level (a.m.s.l) in the western escarpment to $120 \mathrm{~m}$ a.m.s.l. on the eastern boundary. Flow patterns within these rivers are highly variable and seasonal, with coefficients of variation (\%) for mean daily flow rates from 1950 to 2000 ranging from 200 to $600 \%$ (Rivers-Moore, 2003). The eastern portion of the catchment is dominated by the 


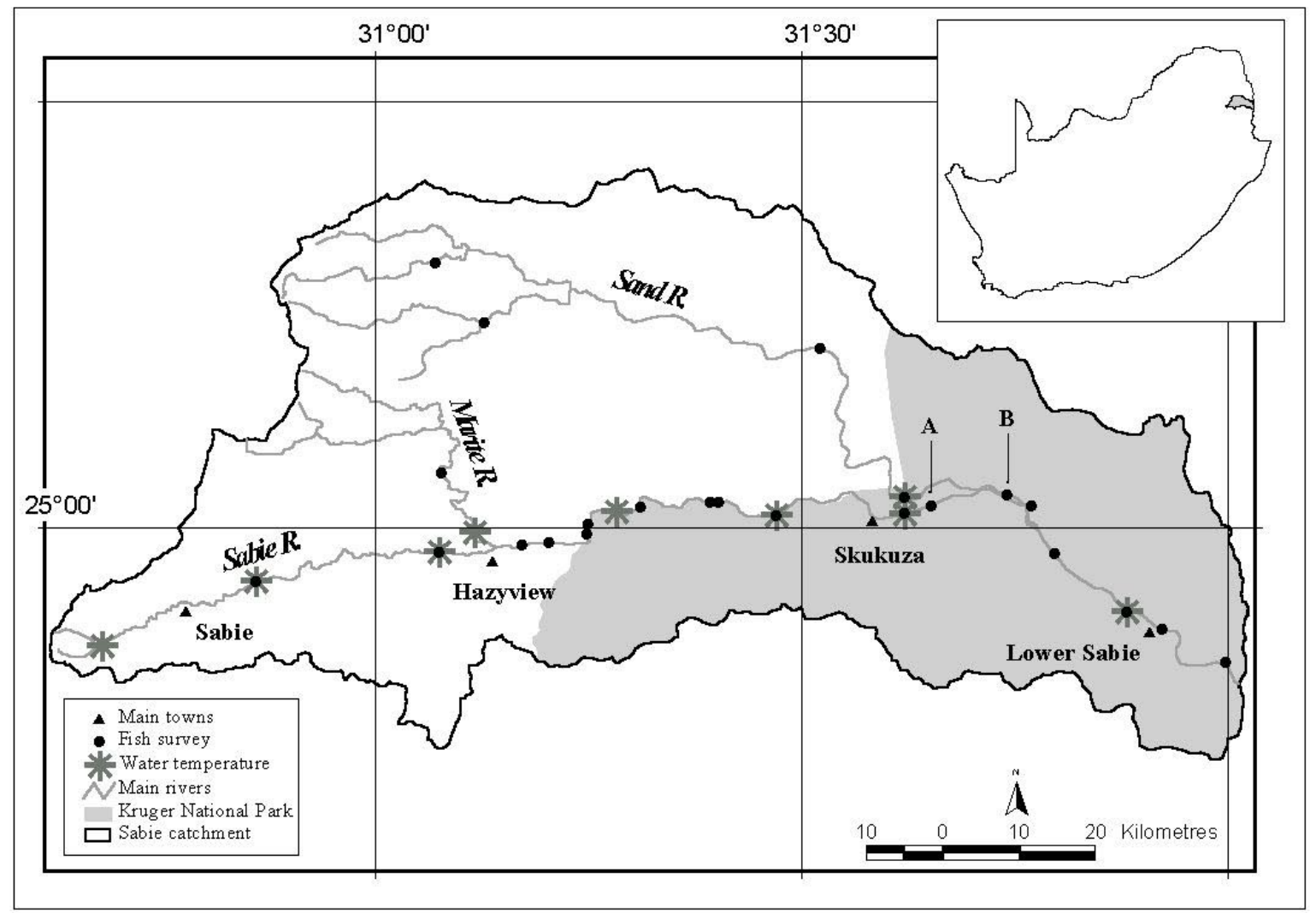

Figure 1

Combined May and October electro-fishing survey sites for Chiloglanis sampling within the Sabie catchment, together with location of water temperature survey sites. Points A-B refer to a critical thermal reach for $C$. anoterus within the Sabie River, which is $128-138 \mathrm{~km}$ downstream from the top of the catchment.

Kruger National Park, while significant areas are afforested in the higher western region.

\section{Calculation of water temperature threshold for C. anoterus}

Standard electro-fishing techniques using a $220 \mathrm{v}$ generatorpowered electro-shocker were used to sample 21 riffle sites over five- to ten-day periods within the Sabie River during October 2000 and 2001, and May 2000, 2001 and 2002 (Fig. 1). May and October were chosen because these months coincided with the extensive electro-fishing surveys of Weeks et al. (1996), and because they preceded and succeeded winter flows, allowing for site accessibility. Sites ranged from $867 \mathrm{~m}$ a.m.s.l. to 131 $\mathrm{m}$ a.m.s.l, with 16 located on the Sabie River, four on the Sand River and one on the Marite River. Gender, length ( $\mathrm{mm})$ and mass ( $\mathrm{g}$ ) for C. anoterus adult individuals were recorded. Unadjusted relative abundance numbers were used to plot an abundance curve of $C$. anoterus.

Daily maximum water temperatures were obtained by taking the highest hourly water temperature recorded over a twenty-four hour period using $\mathrm{Hobo}^{\circledR}$ single-channel data loggers (Onset, 1999) at nine sites within the Sabie catchment from 1 June 2001 to 31 May 2002. Observed water temperatures were related to twelve of the electro-fishing sites due to their relative proximity (Fig. 1), although coincident water temperature records were only available from June 2001 onwards. For the remaining sites on the Sabie River, water temperatures were interpolated by assuming a linear increase in daily maximum water temperatures with downstream distance. For three of the sites on the upper Sand River, water temperatures were simulated using a simple linear regression model (Eq. (1); $\mathrm{R}^{2}=0.84$ ) based on mean daily air temperatures that were adjusted for altitude (Rivers-Moore, 2003):

$$
W T_{\max }=3.711+0.916^{*} A T_{\text {mean }}
$$

where:

$W T_{\max }$ is maximum daily water temperature

$A T_{\text {mean }}^{\text {max }}$ is mean daily air temperature.

\section{Maximum weekly average temperature (MWAT) that should not be exceeded}

(Brungs and Jones 1977; Armour 1991), which has previously been used to determine temperature thresholds for coho salmon Oncorhynchus kisutch, was used to calculate a critical threshold temperature (TT) for C. anoterus (Eq. (2)), using a relative abundance curve of $C$. anoterus along the longitudinal axis of the Sabie River as an initial starting point. While it is recognised that $C$. anoterus (a species occurring in cooler water habitats in the upper reaches of the Sabie River, but able to tolerate warmer water) and $O$. kisutch (a cold water species) are unrelated species, this temperature threshold metric was applied to C. anoterus in the absence of suitable metrics being available through similar research for fish in Southern African rivers.

$$
T T=O T+(U U I L T-O T) / 3
$$


where:

$O T$ is species-specific optimal temperature

UUILT is the upper temperature tolerance for the species of fish being considered.

The frequency of TT exceedance for the period 1 June 2001 to 31 May 2002 was calculated based on a seven-day moving average of daily maximum water temperatures. This is a similar approach to that used by Robison et al. (1999), who suggested characterizing water temperatures using a seven-day moving average of maximum water temperatures, as a measure representing prolonged exposure by aquatic life to high temperatures. It was assumed that the cumulative amount of heating between years would remain constant on a short-term (intra-decadal) basis, and that the use of a smoothing technique such as a $7 \mathrm{~d}$ moving average would negate any differences, thereby allowing the June 2001 - May 2002 water temperature time series to be applied to all electro-fishing surveys. A logistic regression model was calculated using the presence (1) or absence $(0)$ of C. anoterus at 21 sites, to estimate the probability of occurrence of $C$. anoterus as a function of TT exceedance.

\section{C. anoterus condition factor index (CFI)}

This index is based on the assumption that the average condition of $C$. anoterus adults declines with downstream distance, due to prolonged thermal stress. Due to allometric scaling between body mass and body length in fish (Eq. (3a)) (Ricker, 1968; Peters, 1983; McEwan and Hecht, 1984; Schmidt-Nielsen, 1984), condition factors were calculated for $C$. anoterus by dividing mass ( $\mathrm{g}$ ) by length (mm), according to Eq.(3b).

$$
\begin{aligned}
& M=a L^{b} \\
& C F=\frac{M}{I^{b}}
\end{aligned}
$$

where:

$M$ is body mass ( $\mathrm{g}$ )

$L$ is body length (mm)

$a$ is the proportionality coefficient or intercept

$b$ is the exponent or slope; and $C F$ is the condition factor.

Differences between condition factors based on sampling dates, and gender, were tested using one-way analyses of variance (no blocking). ANOVAs of length, mass and condition versus sampling dates (May 2000, October 2000, May 2001 and May 2002); and length, mass and condition vs. gender (male and female), were performed, with the hypothesis $(p<0.01)$ that sampling dates and gender had no effect on body length, mass or condition. While it is recognised that condition factor is not independent of length or mass, being a function of both of these, it nevertheless represents a useful measure of the relationship between length and mass. Due to the inter-annual variation in condition, condition factors based on data from all five electro-fishing surveys were combined to provide a larger data set, although it is recognised that a more reliable relationship between condition and downstream distance should be based on data collected at the same time each year, for a number of years. A box-and-whisker plot was used to illustrate the relationship between condition factor variability and downstream distance. A final step in using the condition factor as an index of thermal change was to determine whether a trend existed between the condition factor, and downstream distance $(\mathrm{km})$ along the longitudinal axis of the Sabie River.

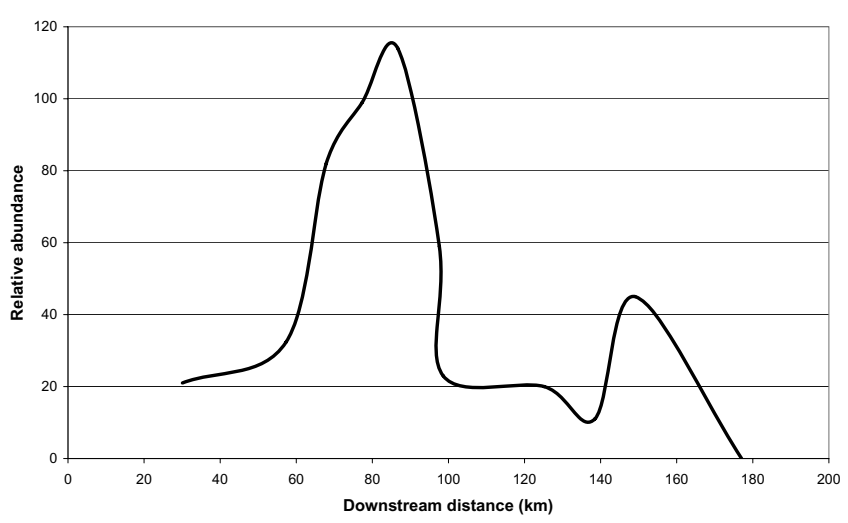

Figure 2

Relative abundance curves of C. anoterus for May 2001 electro-fishing survey

\section{Results}

\section{Water temperature threshold}

The TT for $C$. anoterus was calculated using Eq. (2) to be $25^{\circ} \mathrm{C}$. $O T$ was estimated by taking the midpoint in the temperature range of $C$. anoterus, which was in turn estimated using the absolute minimum $\left(10.3^{\circ} \mathrm{C}\right)$ and maximum $\left(31.5^{\circ} \mathrm{C}\right)$ hourly water temperatures recorded at the upper and lower sites that C. anoterus was recorded at throughout the survey period (Rivers-Moore, 2003). A typical species distribution curve based on relative abundances of $C$. anoterus for May 2001, which was the most comprehensive survey along the longitudinal axis of the Sabie River, is provided in Fig. 2. In the absence of available data, UUILT was conservatively estimated by adding two degrees to the upper limit temperature. Sensitivity analyses were undertaken on the threshold temperature by adjusting the UUILT by $\pm 2^{\circ} \mathrm{C}$ (i.e. 0 and $4^{\circ} \mathrm{C}$ ), which gave TT values of 24.3 and $25.7^{\circ} \mathrm{C}$ respectively.

Annual frequency of exceedance of a $25^{\circ} \mathrm{C}$ TT is shown in Table 1. A subset of the annual frequency of exceedance of TT for the Sabie River was plotted as a function of downstream distance (Fig. 3), as well as the TT values of 24.3 and $25.7^{\circ} \mathrm{C}$, as part of the sensitivity analyses. Similar trends were apparent for all three TT values. The annual probability of occurrence $(p)$ $(\mathrm{p}<0.001)$ of $C$. anoterus was calculated for the annual frequency (Eq. (4)) of exceedance of a $25^{\circ} \mathrm{C}$ TT in the range 0 to $240 \mathrm{~d}$ (Fig. 4). The annual frequency of exceedance of TT at which the probability of not finding $C$. anoterus vs. finding $C$. anoterus at a site was greater than 0.5 was $196 \mathrm{~d}$. Additonally, annual probabilities of occurrence were calculated for TT of 24.3 and $25.7^{\circ} \mathrm{C}$ as part of the sensitivity analyses of this model. These threshold values had the effect of increasing or decreasing the annual frequency of exceedance of TT, at which the probability of not finding C. anoterus at a site was greater than 0.5 , from $196 \mathrm{~d}$ to 225 and $173 \mathrm{~d}$ respectively.

$$
p=\frac{e^{12.990-0.066(x)}}{1+e^{12.990-0.066(x)}}
$$

where:

$x$ is annual $25^{\circ} \mathrm{C}$ TT exceedance.

\section{C. anoterus CFI}

The relationship between mass and length for $C$. anoterus was shown to be significant $\left(n=360 ; \mathrm{R}^{2}=0.85\right)$ ( Fig. 5$)$, and could 


\begin{tabular}{|c|c|c|c|c|c|}
\hline \multicolumn{6}{|c|}{$\begin{array}{c}\text { TABLE 1 } \\
\text { Presence or absence (P/A) of } C \text {. anoterus, and } \\
\text { frequency of exceedance of three TT based } \\
\text { on seven-day moving average of maximum } \\
\text { daily water temperatures from } 31 \text { May } 2001 \text { to } \\
30 \text { June } 2002\end{array}$} \\
\hline $\begin{array}{l}\text { Site } \\
\text { No. }\end{array}$ & \begin{tabular}{|l|} 
Down- \\
stream \\
distance \\
$(\mathrm{km}) /$ river
\end{tabular} & P/A & $\begin{array}{l}24.3^{\circ} \mathrm{C} \\
\text { TT (d) }\end{array}$ & $\begin{array}{l}25.0^{\circ} \mathrm{C} \\
\text { TT (d) }\end{array}$ & $\begin{array}{l}25.7^{\circ} \mathrm{C} \\
\text { TT (d) }\end{array}$ \\
\hline $\mathrm{Ca} 1$ & 30.09 & 1 & 0 & 0 & 0 \\
\hline $\mathrm{Ca} 2$ & 57.29 & 1 & 5 & 0 & 0 \\
\hline $\mathrm{Ca} 3$ & 67.88 & 1 & 91 & 65 & 44 \\
\hline $\mathrm{Ca} 4$ & 71.20 & 1 & 123 & 88 & 60 \\
\hline $\mathrm{Ca} 5$ & 77.34 & 1 & 164 & 138 & 98 \\
\hline $\mathrm{Ca} 6$ & 86.69 & 1 & 164 & 138 & 98 \\
\hline $\mathrm{Ca} 7$ & 98.62 & 1 & 205 & 167 & 124 \\
\hline $\mathrm{Ca} 8$ & 106.58 & 1 & 217 & 195 & 153 \\
\hline $\mathrm{Ca} 9$ & 125.17 & 1 & 213 & 182 & 144 \\
\hline Ca10 & 128.24 & 1 & 213 & 182 & 144 \\
\hline Ca11 & 138.48 & 1 & 227 & 202 & 176 \\
\hline Ca12 & 141.40 & 0 & 231 & 203 & 182 \\
\hline Ca13 & 149.14 & 1 & 239 & 207 & 191 \\
\hline Ca14 & 156.10 & 0 & 243 & 212 & 201 \\
\hline Ca15 & 165.66 & 0 & 243 & 212 & 201 \\
\hline Ca16 & 177.05 & 0 & 243 & 212 & 201 \\
\hline Ca17 & Marite River & 1 & 138 & 106 & 76 \\
\hline Ca18 & Sand River & 0 & 214 & 205 & 201 \\
\hline Ca19 & Sand River & 0 & 186 & 168 & 132 \\
\hline $\mathrm{Ca} 20$ & Sand River & 1 & 169 & 137 & 84 \\
\hline $\mathrm{Ca} 21$ & Sand River & 1 & 162 & \begin{tabular}{|l|}
127 \\
\end{tabular} & 78 \\
\hline
\end{tabular}

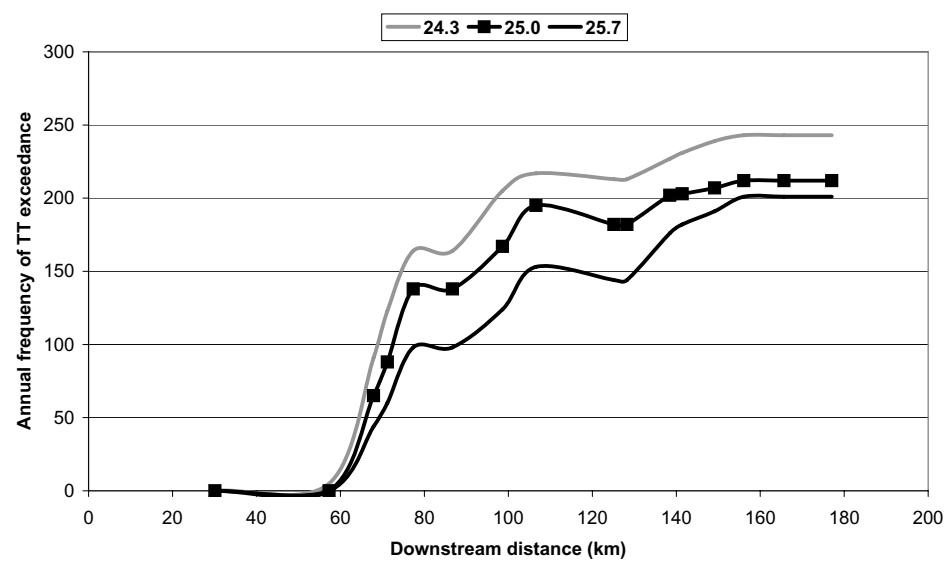

Figure 3

Observed annual frequency of exceedance of a $25.0^{\circ} \mathrm{C} T$ for $\mathrm{C}$. anoterus, as a function of downstream distance and based on daily maximum water temperatures between 1 June 2001 and 31 May 2002. Plots for TT values of 24.3 and $25.7^{\circ} \mathrm{C}$ are also shown

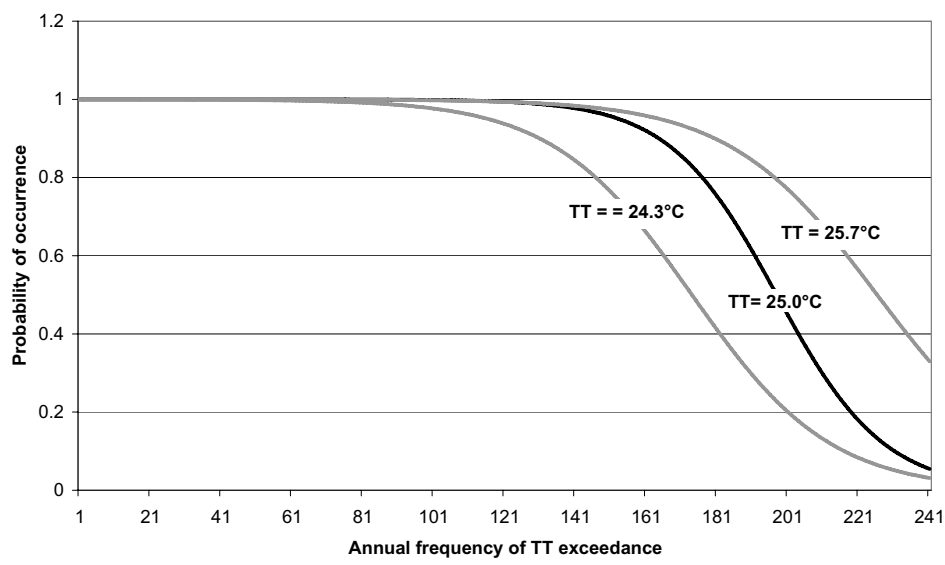

Figure 4

be predicted by Eq. (5).

$$
M=0.1121 e^{0.0582 L}
$$

Probability of occurrence of $C$. anoterus with annual cumulative frequency of exceedance of a $25.0^{\circ} \mathrm{TT}$, based on combined presence/absence data from five electro-fishing surveys from 2000-2002. Probability plots based on TT values of 24.3 and $25.7^{\circ} \mathrm{C}$ are shown as part of a sensitivity analysis

$M$ is mass $(\mathrm{g})$

$L$ is length $(\mathrm{mm})$.

Based on the analyses of variance to test for the effects of sampling date and gender on the length, mass and conditions of $C$. anoterus adults, length did not vary between sampling dates, but mass and condition did vary significantly $(\mathrm{p}<0.01)$ between sampling dates (Table 2). Conversely, length tended to be significantly greater for males than females $(\mathrm{p}<0.01)$, although there were no significant differences in mass or condition between male and female $C$. anoterus adults (Table 3). Thus, in calculating the condition index, data for lengths and masses of male and female $C$. anoterus need not be separated.

A box-and-whisker plot (Fig. 6) of condition factor (as a combined data set from all five electro-fishing surveys for the sites on the Sabie River; $n=629$ ) vs. downstream distance the Sabie River showed that, while the range in condition factor was greatest at the upstream sites, the median condition factor was highest upstream, and decreased with downstream distance.

The linear relationship between the mean condition factors of $C$. anoterus and downstream distance

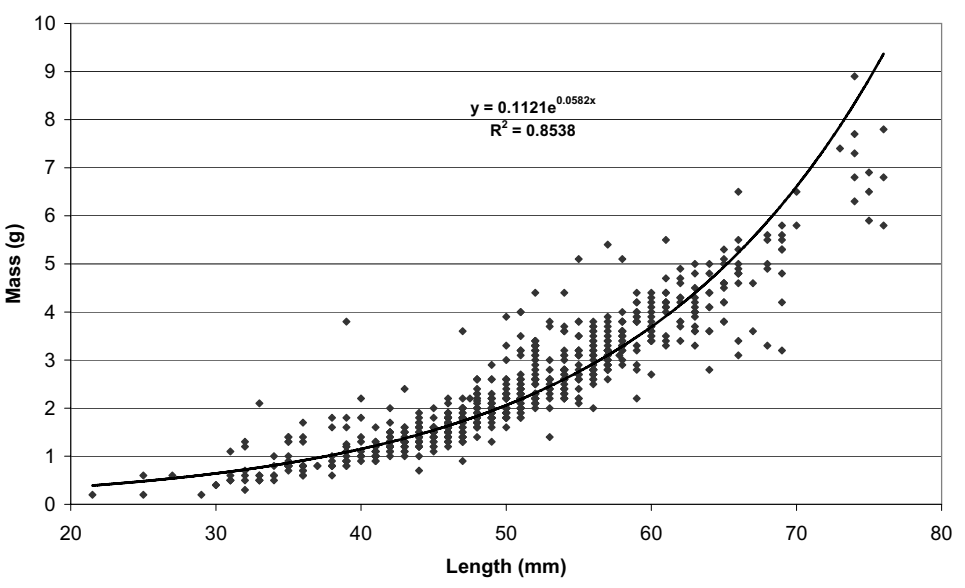

Figure 5

Relationship between mass $(\mathrm{g})$ and length $(\mathrm{mm})$ for $\mathrm{C}$. anoterus, based on pooled data from electro-fishing surveys between May 2000-2002 and October 2000 


\begin{tabular}{|l|l|l|l|l|}
\hline \multicolumn{5}{|c|}{$\begin{array}{c}\text { TABLE 2 } \\
\text { differences between length, mass and condition } \\
\text { based on sampling date }\end{array}$} \\
\hline Sample date & $\begin{array}{l}\text { Sample } \\
\text { size (n) }\end{array}$ & $\begin{array}{l}\text { Mean } \pm \text { s.d. } \\
\text { length (mm) }\end{array}$ & $\begin{array}{l}\text { Mean } \pm \text { s.d. } \\
\text { mass (g) }\end{array}$ & $\begin{array}{l}\text { Mean } \pm \text { s.d. } \\
\text { condition }\end{array}$ \\
\hline May 2000 & 61 & $48.12 \pm 11.30$ & $1.98 \pm 1.42$ & $1.57 \pm 1.10$ \\
\hline October 2000 & 159 & $52.05 \pm 9.12$ & $2.83 \pm 1.31$ & $2.24 \pm 1.02$ \\
\hline May 2001 & 430 & $50.42 \pm 8.27$ & $2.31 \pm 1.18$ & $1.84 \pm 0.92$ \\
\hline May 2002 & 117 & $50.33 \pm 10.65$ & $2.70 \pm 1.54$ & $2.14 \pm 1.20$ \\
\hline F-value & 0.033 & $<0.001^{*}$ & $<0.001^{*}$ \\
\hline $\begin{array}{l}\text { * Significant difference (in length, mass or condition) between } \\
\text { sample dates (p }<0.01)\end{array}$ \\
\hline
\end{tabular}

\begin{tabular}{|c|c|c|c|c|}
\hline \multicolumn{5}{|c|}{ 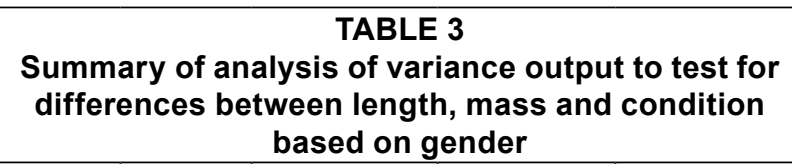 } \\
\hline Gender & & & & \\
\hline & & & & \\
\hline IVTat & & & & \\
\hline \multicolumn{2}{|l|}{ F-value } & $0.005^{*}$ & 0.034 & 0.035 \\
\hline
\end{tabular}

along the Sabie River was calculated using the May 2001 data as this survey gave the most comprehensive distribution of sites along the longitudinal axis of the Sabie River. Based on these data, the condition factor was shown to decrease with downstream distance (Fig. 7) $\left(\mathrm{R}^{2}=0.71\right)$. Mean condition factors of C. anoterus remained within a $10 \%$ envelope of the regression line between condition and downstream distance (Eq. (6)), with the exception of the sites $30(\mathrm{Ca} 1)$ and $86(\mathrm{Ca} 6) \mathrm{km}$ downstream from the source of the Sabie River.

May 2001: $C F=-0.0112($ downstream distance $)+2.8277_{[6]}$

\section{TPC for thermal heating in the Sabie River}

The cumulative water temperature threshold at which the probability of finding $C$. anoterus was less than 0.5 was chosen as the threshold water temperature value of concern. It is proposed that exceedance of the C. anoterus TT of $25^{\circ} \mathrm{C}$ by $196 \mathrm{~d}$ according to a $7 \mathrm{~d}$ moving average of maximum daily water temperatures of the Sabie River for the annual period 1 June to 31 May provides a TPC that can be usefully applied by river managers monitoring this system. This coincides with the thermal reach extending from $128 \mathrm{~km}$ downstream from the top of the catchment to 138 $\mathrm{km}$ downstream (Fig. 1, points A to B). Sensitivity analyses based on changing the UUILT by $\pm 2{ }^{\circ} \mathrm{C}$ showed that the 'critical' thermal reach for $C$. anoterus moved downstream (to $c a$. 130 to $140 \mathrm{~km}$ ) for a TT of $24.3^{\circ} \mathrm{C}$, while it remained unchanged for a TT of $25.7^{\circ} \mathrm{C}$, based on the data resolution in this research. Biological indicators of the TPC are the presence of $C$. anoterus, and the average condition factor of these fish during May of each year. The correlation between a $25^{\circ} \mathrm{C}$ TT and condition factor provides a quantifiable measure of exceedance of this TPC (Fig. 8). The relationship between the frequency of exceedance of TT and condition is generally inversely proportional, with condition decreasing as the duration of TT exceedance increases.

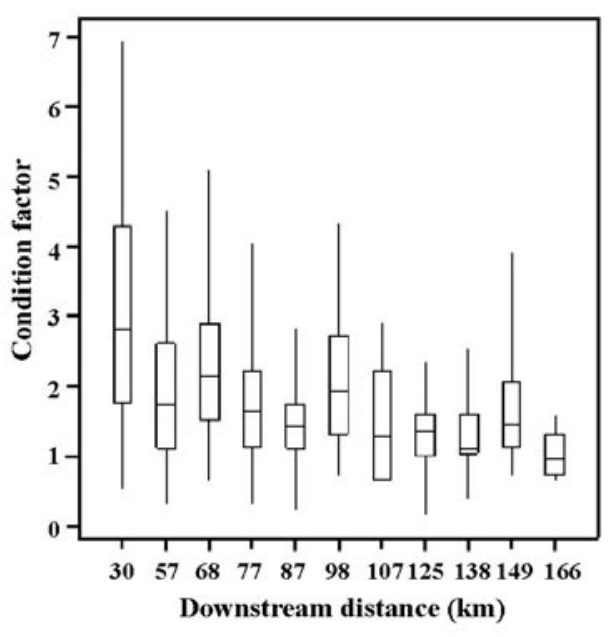

Figure 6

Box-and-whisker plot of condition factor (mass to length ratio) of $C$. anoterus adults vs. site, based on pooled data from electrofishing surveys listed in Fig. 5. Whiskers show maximum and minimum values, while the box shows the middle $50 \%$ of the data, with the median shown as a line within the box.

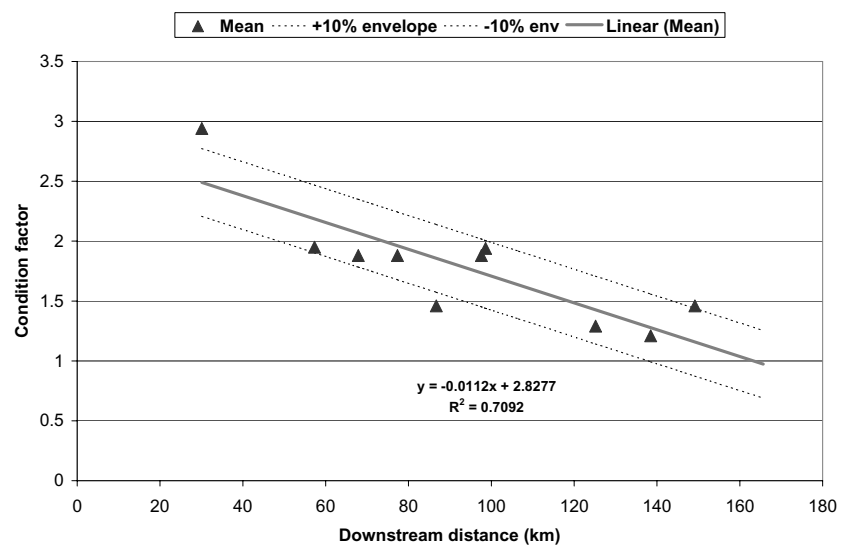

Figure 7

Condition index for C. anoterus with downstream distance along the longitudinal axis of the Sabie River.

The predicted average fish condition factors for this reach, calculated from Eq.(6), are 1.39 and 1.28 respectively.

\section{Discussion}

\section{General considerations}

The approach described in this paper provides a generic technique for linking an abiotic stressor to a biotic index, thereby providing an initial means for assessing ecologically significant warming trends in Southern African river systems. Fish condition factor indices and presence/absence data have the potential to be used as surrogate measures of the degree of heating within different Southern African river systems, as highlighted by this research on sections of the Sabie River. The logistic regression model provides a useful technique for choosing a threshold temperature corresponding to a chosen probability of finding adults of C. anoterus within certain river reaches, since the probability of occurrence of $C$. anoterus could be linked to an annual index of heating within the Sabie River. Simple sensitivity analyses showed that the approach proposed in this research is robust. 
Figure 8

Correlative relationship between average condition of $C$. anoterus and annual frequency of exceedance of a $T T$ of $25^{\circ} \mathrm{C}$ for $\mathrm{C}$. anoterus. Results of the sensitivity analyses using $T T$ values of 24.3 and $25.7^{\circ} \mathrm{C}$ are also shown

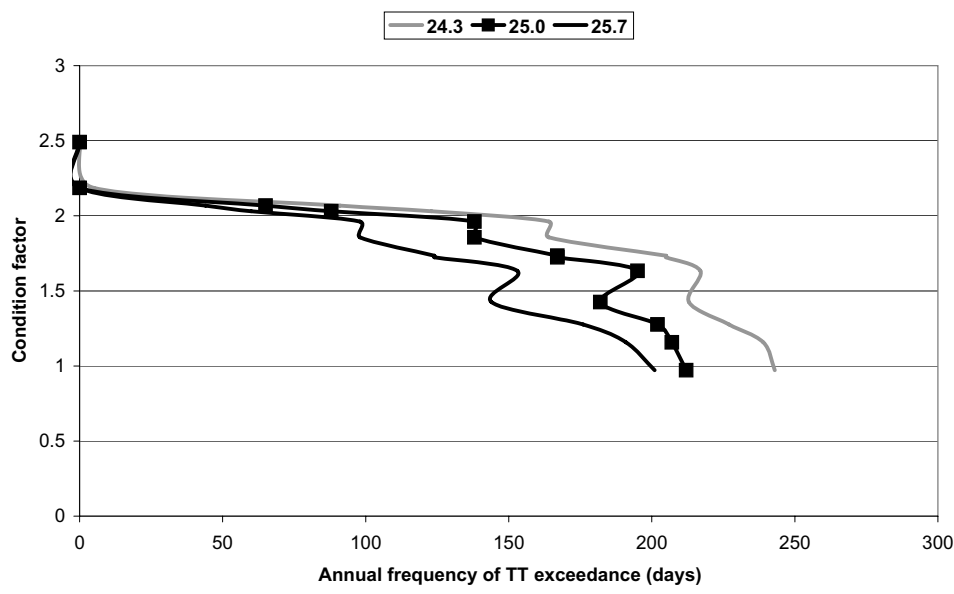

The use of a CFI has the advantage of being independent of relative abundances, which is significant since population size in fish has been shown to be highly variable both temporally and spatially (Harris, 1995; Jobling, 1995), and discerning the importance of natural vs. anthropogenic changes using abundances is difficult (Harris, 1995). A fish condition factor has the potential to be used as a suitable index to reflect annual changes in water temperatures. However, such condition factors are recognised as contentious, being potentially confounded by additional sources of variability such as nutrition, season, maturity of individuals, gender, intra- and inter-specific competition and the life stage sampled (Ricker, 1968). Adult C. anoterus fish may lose condition in the downstream reaches of the Sabie River due to factors other than water temperatures, such as increased predation and inter-specific competition associated with the increase in species diversity and richness. Nevertheless, the CFI provides a practical means for river managers to evaluate average population response of $C$. anoterus to thermal stress.

\section{Usefulness of TPCs and system thresholds}

Given their importance, changes in water temperatures are likely to have substantial impacts on the fish communities in Southern African rivers, including those of the Sabie catchment. These are likely to be a consequence of changes in the drivers and buffers of water temperatures, including, inter alia, flow volumes and air temperatures. Hydro-ecological science and management should aim to understand species patterns, as a reflection of abiotic and biotic processes acting on individuals at the micro scale (Vannote et al., 1980; Frissel et al., 1986). Unravelling these complex species patterns in the context of environmental drivers has been described as 'ecological detection' by Hilborn and Mangel (1997). Such hydro-ecological studies are increasingly interdisciplinary, with research focussing on, inter alia, the relationships between water quantity and quality, the importance of variability and scale, and the use of biological indicators of river health. A growing awareness of the complexity of natural systems is being encapsulated within management strategies, which are moving away from rigid approaches towards strategies that recognise uncertainty. There is a growing recognition, particularly since the 1980 s, of the importance of variability in maintaining river health (see for example Schindler, 1987; Gunderson et al., 1995; Richter et al., 1996; Reynolds, 1998).

The use of TPCs provides a practical means towards managing for system variability, as well as providing testable hypotheses based on the level of system understanding. Funda- mental to defining a robust TPC is to establish baseline conditions (Noss, 1990), since adaptive management initiatives are generally concerned either with ecological restoration of a system, or managing for a desired future state, preferably based on reference conditions. The broader scientific context of the abovementioned points, assuming a need for management of the Sabie catchment's rivers, will be a cycle of ongoing assessment, application/rejection, and refinement of the management approach. Management strategies need to be adapted as new data and insights emerge (Dawe et al., 2000), which can only be achieved with long-term monitoring programmes. This iterative approach aims to reinforce the fundamental science that should underpin effective management of natural systems, as emphasised by Moss (1999).

Since it is not always possible to distinguish managementcaused temperature exceedances from natural conditions (Essig, 1998), long-term environmental monitoring programmes are of increasing importance in distinguishing between natural variation and low-level effects of perturbations in ecosystems (Schindler, 1987). We feel that in order to initially make greater use of the proposed water temperature TPC, a primary research priority is to extend observed water temperature time series for as long as possible, together with subsequent May electrofishing surveys in the Sabie River to test the stability of the C. anoterus CFI to downstream distance relationship. Refinement of the estimated temperature threshold for $C$. anoterus would complement these data.

A pertinent question arising from this research is: 'Are TPCs valid for abiotic drivers over which there is little direct management control?' From a pragmatic management perspective, streamflow within the rivers of the Sabie catchment is the most manageable abiotic parameter. Indirect management of water temperatures is possible by targeting those drivers and buffers of thermal regimes that can be directly managed. This would include appropriate management of riparian zones, the maintenance of natural flow variability, and careful consideration of the economic benefits vs. ecological costs of streamflow regulation through the building of impoundments. Changes in ambient water temperatures, linked to global/regional climate change, could be managed by ensuring that the system has the capacity to respond i.e. that it retains its resilience. A second identified research priority is therefore a focus on system resilience, which should include an understanding of the contributions of seasonality and variability to river ecosystem functioning, as well as the relationships between these and 'manageable' components, of the thermal regimes of the main rivers of the Sabie catchment. 
One research goal, for example, could be to focus on understanding how different fish species respond to changes in water temperatures, and ensuring that movement corridors exist for fish to respond to changes in water temperatures. The use of simple models to generate scenarios of fish response to thermal stress under different environmental conditions (for example, flow reduction or increased air temperatures) is a useful approach, as outlined by Rivers-Moore (2003). Basic ecological studies of key fish species are desirable, focusing on their life-histories and tolerances of environmental stress, such as changes in flow volumes and water temperatures. This should include laboratory studies, although it is recognised that results may not be directly transferable to river systems due to the potential influence of modifying factors not easily mimicked by laboratory studies (Dunham et al., 2003). While laboratory studies may not be able to replicate a species environment (i.e. its realized niche), they are useful in quantifying specie's response to individual abiotic variables, thereby providing a measure of the fundamental niche space for each variable.

We feel that while the approach of using TPCs remains a useful adaptive management tool, a reappraisal of the way in which TPC exceedances are measured is needed. We are unable to say how long a thermal TPC could be exceeded before management actions, if any, should be taken. Such a dilemma could partly be addressed in the future by refining temperature thresholds for both fish and invertebrate species perceived to be of key importance within managed river systems. Adding confidence intervals to such thresholds might provide a suitable 'trigger' response once a threshold has been exceeded beyond its confidence limits, within the context of a broader understanding of system variability. The proposed TPC only becomes useful within a broader scientific context by identifying the natural range of system variability, particularly on a long-term basis, and recognising when this has been exceeded (Schindler, 1987). A TPC for water temperature within the Sabie River, in its current state, nevertheless remains useful to river managers, as it provides an additional indication of system stress, ideally within a suite of TPCs aimed at detecting system change at a range of spatial and temporal scales.

\section{Acknowledgements}

We gratefully acknowledge the Water Research Commission and the University of Natal Research Fund for funding. Thanks are also due to the Kruger National Park's Scientific Services for field assistance, as well as the following people, for access to their properties: Roy Charsley; Barrie and Michelle Pretorius; and Alex and Natalie Durr. Our thanks are also due to Rob Hart of the School of Botany and Zoology, University of KwaZuluNatal, for comment on the use of condition factors.

\section{References}

ARMOUR CL (1991) Guidance for evaluating and recommending temperature regimes to protect fish. Biol. Rep. 90 (22) 13 pp. http:// www.krisweb.com/biblio/general/usfws/armour.pdf Accessed on 15 June 2002

BRAACK L (ed.) (1997) An Objectives Hierarchy for the Management of the KNP. A Revision of Parts of the Management Plan for the Kruger National Park. http://www.parks-sa.co.za Accessed on 1 December 2003.

BRUNGS WA and JONES BR (1977) Temperature Criteria for Freshwater Fish: Protocol and Procedures. US Environmental Protection Agency Environmental Research Laboratory. Duluth, Minn. EPA600/3-77-061
CAISSIE D, EL-JABI N and SATISH MG (2001) Modelling of maximum daily water temperatures in a small stream using air temperatures. J. Hydrol. 251 14-28.

CLASKA ME and GILBERT JJ (1998) The effect of temperature on the response of Daphnia to toxic cyanobacteria. Freshwater Biol. 39 221-232.

CRASS RS (1960) Notes on the freshwater fishes of Natal with descriptions of 4 new species. Annals of the Natal Museum 14 405-458.

DAWE NK, BRADFIELD GE, BOYD WS, TRETHEWEY DEC and ZOLBROD AN (2000) Marsh creation in a northern Pacific estuary: Is thirteen years of monitoring vegetation dynamics enough? Conserv. Ecol. 4 (2) 12[online]. http://www.ecologyandsociety. org/vol4/iss2/art12 Accessed on 8 March 2004.

DUNHAM J, SCHROETER R and RIEMAN B (2003) Influence of maximum water temperature on occurrence of Lahontan Cutthroat trout within streams. N. Am. J. Fish. Manage. 23 1042-1049.

EATON JG and SCHELLER RM (1996) Effects of climate on fish thermal habitat in streams of the United States. Limnol. Oceanogr. 41 (5) 1109-1115

ELLIOTT JM (1994) Quantitative Ecology and the Brown Trout. Oxford University Press, Oxford.

ERASMUS BN, VAN JAARSVELD AS, CHOWN SL, KSHATRIYA $M$ and WESSELS KJ (2002) Vulnerability of South African animal taxa to climate change. Global Change Biol. 8 679-693.

ESSIG DA (1998) The Dilemma of Applying Uniform Temperature Criteria in a Diverse Environment: An Issue Analysis. Idaho Division of Environmental Water Quality, Boise, Idaho. $<$ http:/ $/$ www. krisweb.com/biblio/general/misc/essigidahotemp.pdf Accessed on 15 June 2003.

FRISSEL CA, LISS WJ, WARREN CE and HURLEY MD (1986) A hierarchical framework for stream habitat classification: viewing streams in a watershed context. Environ. Manage. 10 (2) 199-214.

GUNDERSON LH, HOLLING CS and LIGHT SS (eds.) (1995) Barriers and Bridges to the Renewal of Ecosystems and Institutions. Columbia University Press, New York.

HARRIS JH (1995) The use of fish in ecological assessments. Aust. J. Ecol. 20 65-80

HILBORN R and MANGEL M (1997) The Ecological Detective: Confronting Models with Data. Princeton University Press, Princeton, New Jersey.

HINES D and AMBROSE J (1998) Evaluation of Stream Temperatures Based on Observations of Juvenile Coho Salmon in Northern California Streams. [PDF on Internet]. http://www.krisweb.com/biblio/general/misc/hinesambrose.pdf Accessed on 15 June 2002.

JOBLING M (1995) Environmental Biology of Fishes. Chapman \& Hall, London.

MACKENZIE JA, VAN COLLER AL and ROGERS KH (2000) Rule Based Modelling for Management of Riparian Systems. WRC Report No. 813/1/99. Water Research Commission, Pretoria.

MAJER JD (1993) Ants: Bio-indicators of minesite rehabilitation, land use, and land conservation. Environ. Manage. 7 375-383.

McEWAN A and HECHT T (1984) Age and growth of the longfin eel, Anguilla mossambica Peters, 1852 (Pisces: Anguillidae) in Transkei rivers. S. Afr. J. Zool. 19 (4) 280-285.

MOSS B (1999) Ecological challenges for lake management. Hydrobiol. 395/396 3-11

NOSS RF (1990) Indicators for monitoring biodiversity: A hierarchical approach. Conserv. Biol. 4 355-364

ONSET (1999) Hobo Data Loggers. Onset Computer Corporation, 470 MacArthur Blvd., Bourne, MA 02532.

PETERS RH (1983) The Ecological Implications of Body Size. Cambridge University Press, Cambridge.

REYNOLDS CS (1998) The state of freshwater ecology. Freshwater Biol. 39 741-753.

RICHTER BD, BAUMGARTNER JV, POWELL J and BRAUN DP (1996) A method for assessing hydrologic alteration within ecosystems. Conserv. Biol. 10 (4) 1163-1174.

RICKER WE (ed.) (1968) Methods for Assessment of Fish Production in Fresh Waters. IBP Handbook No. 3. Blackwell Scientific Publications, Oxford

RIVERS-MOORE NA (2003) Water Temperature and Fish Distribution in the Sabie River System: Towards the Development of an Adaptive 
Management Tool. Ph.D. Thesis, University of Natal, Pietermaritzburg, South Africa.

ROBISON EG, RUNYON J and ANDRUS C (1999) Cooperative Stream Temperature Monitoring: Project Completion Report for 1994-1995. Oregon Department of Forestry. http://www.odf.state.or.us/FP MonitoringBMPs/Projects > Accessed on 8 March 2004.

ROGERS K and BESTBIER R (1997) Development of a Protocol for the Definition of the Desired State of Riverine Systems in South Africa. Department of Environmental Affairs and Tourism, Pretoria

ROGERS K and BIGGS H (1999) Integrating indicators, endpoints and value systems in strategic management of rivers of the Kruger National Park. Freshwater Biol. 41 439-451.

SCHINDLER DW (1987) Detecting ecosystem responses to anthropogenic stress. Can. J. Fish. Aquat. Sci. 44 6-25.

SCHMIDT-NIELSEN K (1984) Scaling: Why is Animal Size so Important? Cambridge University Press, Cambridge.

STUCKENBERG BR (1969) Effective temperature as an ecological factor in southern Africa. Zool. Afr. 4 (2) 145-197.
SULLIVAN K, MARTIN DJ, CARDWELL RD, TOLL JE and DUKE S (2000) An Analysis of the Effects of Temperature on Salmonids of the Pacific Northwest with Implications for Selecting Temperature Criteria. Sustainable Ecosystems Institute, Portland, Oregon. http://www.sei.org/downloads/reports/salmon2000.pdf Accessed on 15 June 2002

VANNOTE RL, MINSHALL GW, CUMMINS KW, SEDELL JR and CUSHING CE (1980) The river continuum concept. Can. J. Fish. Aquat. Sci. 37 130-137.

WALTERS C (1997) Challenges in adaptive management of riparian and coastal ecosystems. Conserv. Ecol. 1(2) 1. [online]. http:/ www.ecologyandsociety.org/vol1/iss2/art1 Accessed on 8 March 2004.

WEEKS DC, O'KEEFFE JH, FOURIE A and DAVIES BR (1996) A Pre-impoundment Study of the Sabie-Sand River System, Mpumalanga, with Special Reference to Predicted Impacts on the Kruger National Park. Vol. I: The Ecological Status of the Sabie-Sand River System. WRC Report No. 294/1/96. Water Research Commission, Pretoria. 
